\title{
Characterization and Synthesis of Functionalized Polysilalkylene Siloxane Monomers by Hydrosilylation Reaction
}

\author{
Ronald P. D’Amelia*, Joseph Mancuso, William F. Nirode, Sunaldeep Singh \\ Chemistry Department, Hofstra University, Hempstead, NY \\ *Corresponding author: Ronald.p.damelia@hofstra.edu
}

Received April 27, 2019; Revised June 08, 2019; Accepted June 27, 2019

\begin{abstract}
The synthesis of novel polysilalkylene siloxane monomers is of great interest to industrial chemists owing to their polymeric analogues having extremely useful properties as elastomers, adhesives, fluids, resins, as well as additives to other commercial products. The current industrial process for creating silicone polymers is through hydrosilylation of dienes. This process can produce a wide variety of organosilicon compounds with vast range of uses. The objective of this experiment is to synthesize modified silicone monomers which can be readily hydrolyzed in the presence of water to form their corresponding polymeric analogues. In order to do this, terminal dienes were reacted with either dimethylchlorosilane or methylphenylchlorosilane in the presence of the Karstedt's catalyst, the most commonly used hydrosilylation catalyst, in order to yield the modified siloxane monomers. We report on the methodologies used to determine the identity of the final products as well as the methods used to determine their properties.
\end{abstract}

Keywords: polycarbosiloxanes, organosilicon synthesis, hydrosilylation, fourier transform infrared spectroscopy, nuclear magnetic resonance spectroscopy, Karstedt's catalyst

Cite This Article: Ronald P. D’Amelia, Joseph Mancuso, William F. Nirode, and Sunaldeep Singh, "Characterization and Synthesis of Functionalized Polysilalkylene Siloxane Monomers by Hydrosilylation Reaction.” World Journal of Organic Chemistry, vol. 7, no. 1 (2019): 5-13. doi: 10.12691/wjoc-7-1-2.

\section{Introduction}

Hydrosilylation is frequently used industrially in the preparation of siloxanes and other organosilicon compounds [1-10]. Siloxanes have become ubiquitous in modern day commercial products, becoming a mainstay in the automotive, construction, energy, textile, cosmetic, and adhesives industries [11-20]. Examples of frequently used commercially available products utilizing silicones/siloxanes include: semiconductors, joint sealants, electromagnets, heat-resistant coatings, prosthetics, radiators, and elastomers [20]. The most commonly used industrial homogenous catalyst for this process is known as the Karstedt's catalyst, a $\mathrm{Pt}(0)$ complex, catalytic compound. The structure for the Karstedt's catalyst is shown in Figure 1 and the general mechanisms through which hydrosilylation is thought to occur (The Chalk-Harrod Mechanisms) is shown in Figure 2 [1]. Other catalysts can be used for the purposes of hydrosilylation such as hexachloroplatinic acid with $\mathrm{Pt}_{2}$ (sym-tetramethyldivinyldisiloxane $)_{3}$ as well as various $\mathrm{Ni}, \mathrm{Pd}, \mathrm{Fe}, \mathrm{Os}, \mathrm{Co}, \mathrm{Rh}$, and Ir catalysts [1]. The main advantages of using the Karstedt's catalyst is that the catalyst is homogenous, the entire hydrosilylation reaction can be done in-situ, and yields are consistently high $(>70 \%)$ [1]. Due to the high yields produced by the hydrosilylation reaction, it is the preferred method of synthesizing activated silicone compounds and is a field of critical industrial importance [1]. In order to synthesize the siloxane monomers, 1,5-hexadiene, 1,7-octadiene, diallyl ether, dimethyldivinylsilane, and diallyldimethylsilane were reacted with dimethylchlorosilane as well as methylphenylchlorosilane in the presence of the Karstedt's catalyst. By employing the use of these starting materials, the repeat unit's carbon chain length is altered (1,5-hexadiene versus 1,7-octadiene), an ether functionality is introduced (diallyl ether), as well as another silyl group is added to the backbone of the monomer(dimethyldivinylsilane and diallyldimethylsilane). Different chlorosilanes were utilized in order to further functionalize the siloxane monomers to have either two methyl pendant groups (dimethylchlorosilane) or a methyl and a phenyl pendant group (methylphenylchlorosilane). All of these differences can yield monomers that, when polymerized via condensation polymerization, can create polymers with vastly different applications and commercial uses. The identity of the products produced via hydrosilylation were confirmed via ATR FTIR and ${ }^{1} \mathrm{H}$ NMR analysis of both reactants and products. 
<smiles>C=C[C@H](C=C[Si](C)(C)O[Si](C)(C)C)C=C[Si](C)(C)O[Si](C)(C)C=CC1C=C[Si](C)(C)O[Si](C)(C)C=C1</smiles>

Figure 1. Structure of the Karstedt's Catalyst

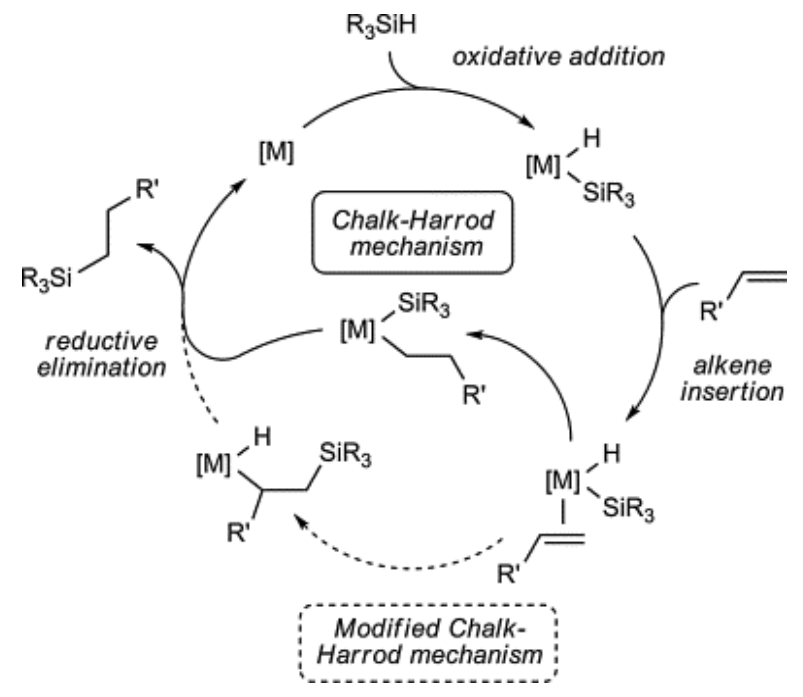

Figure 2. Summary of the Hydrosilylation Reaction Mechanism

\section{Materials and Methods}

\subsection{Chemicals and Instruments}

All of the starting reagents used were liquids at room temperature and were purchased either from Gelest Inc. or Sigma-Aldrich with no further purification, a list of properties of the starting reagents is summarized in Table 1 . The reactants and products were characterized by FTIR spectroscopy, ${ }^{1} \mathrm{H}$ NMR and refractive index. For the NMR analysis, a $400 \mathrm{MHz}$ JEOL model ECS-400 NMR spectrometer was used. The JEOL Delta NMR control and process software version 5.0.2 (Windows) were used to analyze individual spectrum. Each sample was run with no solvent and without an internal reference standard, as a single pulse single scan, 1D proton NMR with a $0.25 \mathrm{~Hz}$ resolution and a relaxation delay of $5 \mathrm{sec}$, temp $20.7^{\circ} \mathrm{C}$. The NMR tubes used in this study were Wilmad Pyrex glass $5 \mathrm{~mm} \times 7$ " thin wall tubes. For FTIR analysis a Bruker Alpha-P ${ }^{\circledR}$ FTIR spectrometer with a Platinum ${ }^{\circledR}$ attenuated total internal reflectance (ATR) quick snap module with a diamond crystal was used. The Alpha-P unit has a Michelson Interferometer with a SiC globar as the IR source, the time dependence of the IR intensity is measured with a pyroelectric DTGS detector. The data analysis was done using the Bruker OPUS ${ }^{\circledR}$ software version 7.0.122. The spectra were displayed as absorbance vs frequency in wavenumbers ranging from 500 to $4000 \mathrm{~cm}^{-1}$. All samples were analyzed as is other than being pressed between the anvil and the diamond crystal of the ATR unit in the liquid phase. The samples were measured using 16 scans at a resolution of $4 \mathrm{~cm}^{-1}$. The refractive index of both the starting reagents and final products were measured using an Abbey refractometer at $20^{\circ} \mathrm{C}$ using the yellow D line from a sodium vapor lamp, light at a wavelength of 589nm. Two or three drops of sample was placed on the open prism. Light was positioned for maximum brightness and chromatic adjustment was made until the demarcation line was sharp and colorless. The purity of the reactants was assessed on TLC plates.

\subsection{General Methods for Synthesis of Dichloro Monomer}

An overview for the overall synthetic procedure is shown in the generalized reaction scheme shown in Figure 3. The hydrosilylation reaction was performed in a three (3) neck round bottom flask (19/22) containing either a dry ice or water- cooled condenser with a $\mathrm{CaCl}_{2}$ drying tube attached, a dropping funnel for the slow addition of chlorosilane, and an adapter to hold both a thermometer and $\mathrm{N}_{2}$ inlet tube. A magnetic stir bar was used to constantly stir the reaction mixture. The hydrosilylation reaction was performed by the slow addition of an appropriate stoichiometric (2.1x) amount of chlorosilane to a mixture of stoichiometric (x) amount of diene along with an approximate $0.6 \mathrm{ml}$ of a $2 \%$ solution of Karstedt's catalyst in xylene. The reaction was performed without any solvent, under $\mathrm{N}_{2}$ atmosphere and at an initial starting temperature of $23^{\circ} \mathrm{C}$ (R.T.). These conditions provided for a homogeneous reaction system. The reaction is extremely exothermic, and the reaction media turned dark brown upon the initial addition of chlorosilane. The temperature rises very rapidly with every few drops of chlorosilane, hence the reaction mixture was cooled to $30^{\circ} \mathrm{C}$ before making another addition of chlorosilane. The reaction, therefore took approximately three (3) hours to complete. After final addition the reaction media was gently refluxed for approximately 2 hours. The hydrosilylation reaction afforded both the mono and di chloro adducts. The products of the reaction were separated under vacuum by fractional distillation

\subsection{Fractional Distillation of the Reaction Mixture}

Fractional distillation under vacuum was performed using a three (3) neck round bottom flask (19/22) [same as used for the hydrosilylation reaction], a Vigreux distillation column - joints 19/22 - column length 170mm, adapter with thermometer, a water jacked condenser and a distillation receiver- radial-straight vacuum adapter with a four (4) fraction cow. Heating unit was a high temperature heating mantel attached to a variac. Vacuum was obtained using a high oil vacuum pump. The first fraction collected boiled at a low temperature and gave a positive olefinic test with $\mathrm{Br}_{2}$ in $\mathrm{CCl}_{4}$. The IR and NMR showed this compound to be the monochloro adduct. The second or last fraction collected came off at a much higher temperature and more material was collected from the last fraction than the first. This material gave a negative test with $\mathrm{Br}_{2}$ in $\mathrm{CCl}_{4}$. The total disappearance of the $\mathrm{C}=\mathrm{C}$ and $\mathrm{Si}-\mathrm{H}$ bonds and the appearance of the Si-Cl bond in the IR confirmed the formation of the dichloro silane compound. Both the mono and dichloro fractions had a water white appearance. 


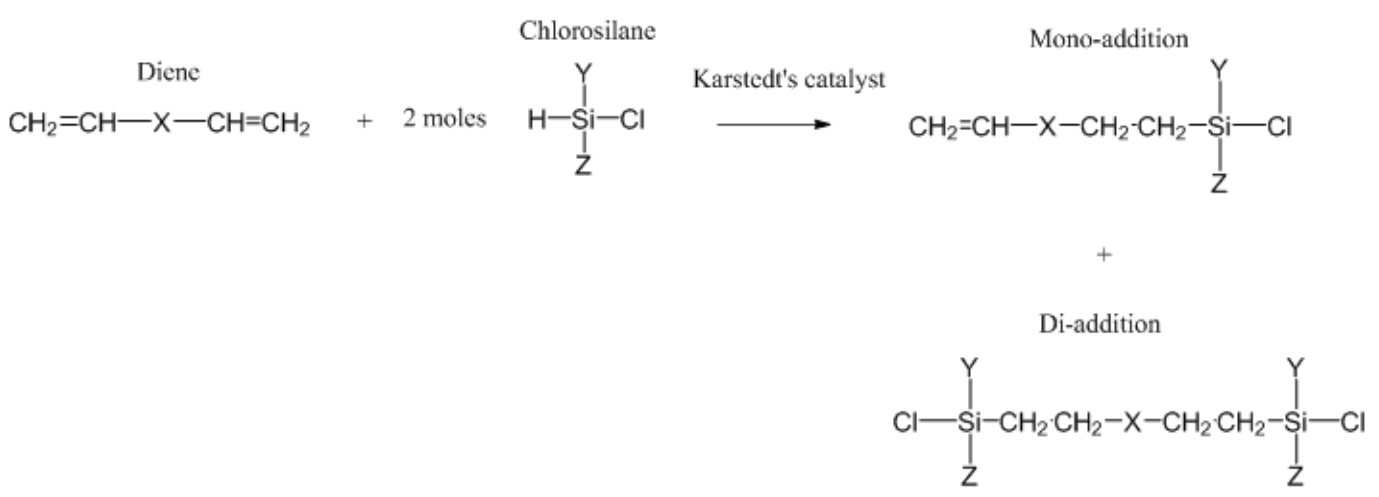

Possible X's

$\mathrm{CH}_{3}$
$\mathrm{Si}$
1
$\mathrm{CH}_{3}$<smiles>C[Si](C)(C)C</smiles>

o

$\mathrm{CH}_{2}-\mathrm{CH}_{2}$

$\mathrm{CH}_{2}-\mathrm{CH}_{2}-\mathrm{CH}_{2}-\mathrm{CH}_{2}$

Possible Y's

$\mathrm{CH} 3$

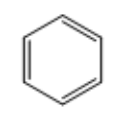

Possible Z's

$\mathrm{CH} 3$

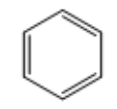

Figure 3. General Hydrosilylation Reaction Scheme for the Development of Hybrid Silicone Monomers

Table 1. Properties of Reactants Used in the Synthesis

\begin{tabular}{|l|l|c|c|c|c|}
\hline Reactant & Formula & M.W. $(\mathrm{g} / \mathrm{mol})$ & $\mathrm{BP}\left({ }^{\circ} \mathrm{C}\right)$ & Density at $25^{\circ} \mathrm{C}$ & Refractive Index \\
\hline 1,5-Hexadiene & $\mathrm{H}_{2} \mathrm{C}=\mathrm{CH}-\mathrm{CH}_{2} \mathrm{CH}_{2} \cdot \mathrm{CH}=\mathrm{CH}_{2}$ & 82.14 & 60 & $0.692 \mathrm{~g} / \mathrm{mL}$ & 1.4025 \\
\hline 1,7-Octadiene & $\mathrm{H}_{2} \mathrm{C}=\mathrm{CH}-\left(\mathrm{CH}_{2}\right) 4-\mathrm{CH}=\mathrm{CH}_{2}$ & 110.2 & $114-121$ & $0.746 \mathrm{~g} / \mathrm{mL}$ & 1.4219 \\
\hline Diallyldimethylsilane & $\left(\mathrm{CH}_{2}=\mathrm{CH}-\mathrm{CH}_{2}\right)_{2}-\mathrm{Si}-\left(\mathrm{CH}_{3}\right)_{2}$ & 140.3 & 54 & $0.768 \mathrm{~g} / \mathrm{mL}$ & 1.4422 \\
\hline Diallylether & $\mathrm{H}_{2} \mathrm{C}=\mathrm{CH}-\mathrm{CH}_{2}-\mathrm{O}-\mathrm{CH}_{2} \cdot \mathrm{CH}=\mathrm{CH}_{2}$ & 98.14 & 95 & $0.803 \mathrm{~g} / \mathrm{mL}$ & 1.4160 \\
\hline Dimethyldivinylsilane & $(\mathrm{CH}=\mathrm{CH})_{2}-\mathrm{Si}-(\mathrm{CH})_{2}$ & 112.24 & $79-82$ & $0.731 \mathrm{~g} / \mathrm{mL}$ & 1.4187 \\
\hline Dimethylchlorosilane & $\left(\mathrm{CH}_{3}\right) 2-\mathrm{SiHCl}$ & 94.62 & 34.7 & $0.852 \mathrm{~g} / \mathrm{mL}$ & 1.3020 \\
\hline Methylphenylchlorosilane & $\mathrm{C}_{6} \mathrm{H}_{5}-\mathrm{SiH}\left(\mathrm{CH}_{3}\right) \mathrm{Cl}$ & 156.68 & 113 & $1.043 \mathrm{~g} / \mathrm{mL}$ & 1.5150 \\
\hline
\end{tabular}

\section{Spectral and Analytical Data}

\subsection{Reactant Spectral Data}

1. 1,5-hexadiene. BP 60 degrees C at STP. FTIR (ATR, $\mathrm{cm}^{-1}$ ) 3079.01 (C-H alkene), 2979.83 (C-H alkane), 2925.55 (C-H alkane), 2845.16 (C-H alkane), 1641.36 (C=C), 992.20 (C=C), 908.76 (C=C). ${ }^{1} \mathrm{H}$ NMR $400 \mathrm{MHz}$ : $6.72 \mathrm{ppm}$ (4 H, triplet), $5.86 \mathrm{ppm}$ (2H, multiplet), 3.06 ppm (4 H, multiplet).

2. 1,7-octadiene. BP 114-121 degrees $\mathrm{C}$ at STP. FTIR (ATR, $\mathrm{cm}^{-1}$ ) 3077.91 (C-H alkene), 2977.93(C-H alkane), 2927.01(C-H alkane), 2856.20(C-H alkane), 1640.67 (C=C), 990.87 (C=C), 908.43 (C=C). ${ }^{1} \mathrm{H}$ NMR $400 \mathrm{MHz}$ : 5.976 ppm (4H, triplet), 5.137 ppm (2H, multiplet), 2.236 ppm (4H, multiplet), $1.582 \mathrm{ppm}$ (4H, multiplet).

3. Dimethylchlorosilane. BP 34.7 degrees C at STP. FTIR (ATR, $\mathrm{cm}^{-1}$ ) 2960.27 (C-H alkane), 2123.20 (Si-H), $1253.52\left(\mathrm{Si}^{-\mathrm{CH}_{3}},\right) 903.04(\mathrm{Si}-\mathrm{H}), 876.74\left(\mathrm{Si}-\mathrm{CH}_{3}\right), 768.97$
(Si-CH $\left.\mathrm{CH}_{3}\right), 490.68$ (Si-Cl). ${ }^{1} \mathrm{H}$ NMR $400 \mathrm{MHz}: 5.38$ ppm (1H, multiplet), $0.982 \mathrm{ppm}(6 \mathrm{H}$, doublet)

4. Dimethyldivinylsilane. BP 79-82 degrees $\mathrm{C}$ at STP. FTIR (ATR, cm ${ }^{-1}$ ) 3059.07 (C-H alkene), 2966.78 (C-H alkane), 1595.96 (Si-C=C), 1004.13 (Si-C=C), 811.74 (C=C). ${ }^{1} \mathrm{H}$ NMR $400 \mathrm{MHz}: 6.965$ ppm (4H, triplet), $6.489 \mathrm{ppm}$ (2H, multiplet), $0.969 \mathrm{ppm}$ (6H, singlet)

5. Diallyldimethylsilane. BP 54 degrees $\mathrm{C}$ at STP. FTIR (ATR, cm ${ }^{-1}$ ) 3078.58 (C-H alkene), 2956.81(C-H alkane), 2913.87 (C-H alkane), 2881.86 (C-H alkane), $1629.84\left(\mathrm{Si}-\mathbf{C H}_{2}-\mathbf{C H}=\mathbf{C H}_{2}\right), 1393.63$ (geminal dimethyl), 1252.05 $\left(\mathrm{Si}-\mathrm{CH}_{3}\right), \quad \mathbf{1 1 5 5 . 0 6}\left(\mathrm{Si}-\mathrm{CH}_{2}-\mathbf{C H}=\mathbf{C H}_{2}\right), \quad \mathbf{8 9 2 . 5 1}$ $\left(\mathbf{S i}-\mathbf{C H}_{2}-\mathbf{C H}=\mathbf{C H}_{2}\right)$. ${ }^{1} \mathrm{H}$ NMR $400 \mathrm{MHz}: 5.821 \mathrm{ppm}$ (4H, triplet), $4.935 \mathrm{ppm}$ (2H, multiplet), $1.614 \mathrm{ppm}$ (4H, triplet), $0.103 \mathrm{ppm}$ (6H, singlet)

6. Diallylether. BP 95 degrees $\mathrm{C}$ at STP. FTIR (ATR, $\mathrm{cm}^{-1}$ ) 3081.14 (C-H alkene), 2983.36(C-H alkane), 2847.61(C-H alkane), 1647.63 (C=C), 1086.51 (C-O), 988.20 (C=C), 918.77 (C=C). ${ }^{1} \mathrm{H}$ NMR $400 \mathrm{MHz}$ : 6.68 
ppm (4H, triplet), 6.046 ppm (2H, multiplet), 4.748 ppm (4H, triplet)

7. Methylphenylchlorosilane. BP 113 degrees $\mathrm{C}$ at STP. FTIR (ATR, $\mathrm{cm}^{-1}$ ) 3070.58 (C-H alkene), 2161.91 (Si-H), 1591.29 (Si-Ph), $1254.91 \quad\left(\mathrm{Si}-\mathrm{CH}_{3}\right), 1117.50$ (Si-Ph), $877.72\left(\mathrm{Si}_{-} \mathrm{CH}_{3}\right), 723.69(\mathrm{Si}-\mathrm{Ph}), 694.64$ (Si-Ph), 457.38 (Si-Cl). ${ }^{1} \mathrm{H}$ NMR 6.456 ppm (1H, triplet), 6.187 ppm (2H, multiplet), 6.173 ppm (2H, multiplet), 4.238 ppm (1H, multiplet), 0.520 (3H, doublet)

\subsection{Product Spectral Data}

1. 1,6-Bis(Chlorodimethylsilyl)Hexane (1a). Bp. $90-92^{\circ} \mathrm{C}$ at $1 \mathrm{mmHg}$. Fourier-Transform Infrared Spectroscopy (FTIR) (ATR, cm ${ }^{-1}$ ): 2961(C-H alkane), 2924(C-H alkane), 2857(C-H alkane), 1407 (C-H alkane), 1252 (Si-CH CH $_{3}, 469$ (Si-Cl); ${ }^{1} \mathrm{H}$ NMR $400 \mathrm{MHz}: 1.513$ (multiplet, 8H, $\mathrm{CH}_{2}$ ), 0.925 (multiplet, 4H, $\mathrm{CH}_{2}$ ), 0.502ppm (singlet, $12 \mathrm{H}, \mathrm{CH}_{3}$ )

2. 1,8-Bis(Chlorodimethylsilyl)Octane (1b). Bp. 128$130{ }^{\circ} \mathrm{C}$ at $1 \mathrm{mmHg}$. FTIR (ATR, $\mathrm{cm}^{-1}$ ): 2960(C-H alkane), 2924(C-H alkane), 2854(C-H alkane), 1462(C-H alkane), $1256\left(\mathrm{Si}-\mathrm{CH}_{3}\right), 790\left(\mathrm{Si}-\mathrm{CH}_{3}\right), 469$ (Si-Cl); ${ }^{1} \mathrm{H}$ NMR 400 MHz: 1.4524 (multiplet, $12 \mathrm{H}, \mathrm{CH}_{2}$ ), 0.9392 (multiplet, $4 \mathrm{H}$, $\mathrm{CH}_{2}$ ), 0.5234ppm (singlet, $12 \mathrm{H}, \mathrm{CH}_{3}$ )

3. 1,1-Bis(chlorodimethylsilylethyl)-1,1-dimethylsilane (1c). Bp. $110^{\circ} \mathrm{C}$ at $0.2 \mathrm{mmHg}$. FTIR (ATR, $\mathrm{cm}^{-1}$ ): 2956(C-H alkane), 2909 (C-H alkane), 1462, (C-H alkane), $1251\left(\mathrm{Si}-\mathrm{CH}_{3}\right), 1134\left(\mathrm{Si}-\mathrm{CH}_{2}-\mathrm{CH}_{2}-\mathrm{Si}\right), 1057\left(\mathrm{Si}-\mathrm{CH}_{2}-\mathrm{CH}_{3}\right)$, 784 (Si-CH $\left.{ }_{3}\right), 468$ (Si-Cl); ${ }^{1} \mathrm{H}$ NMR $400 \mathrm{MHz}: 0.8052$ (multiplet, 4H, $\mathrm{CH}_{2}$ ), 0.6426 (multiplet, $4 \mathrm{H}, \mathrm{CH}_{2}$ ), 0.4707 (singlet, $12 \mathrm{H}, \mathrm{CH}_{3}$ ), 0.1488ppm (singlet, $6 \mathrm{H}, \mathrm{CH}_{3}$ )

4. 1,1-Bis(chlorodimethylsilylpropyl)-1,1-dimethylsilane (1d). Bp. $132{ }^{\circ} \mathrm{C}$ at $0.4 \mathrm{mmHg}$. FTIR $\left(\mathrm{ATR}, \mathrm{cm}^{-1}\right.$ ): 2953 (C-H alkane), 2912(C-H alkane), 1251 (Si-CH $)_{3}$, $1200\left(\mathrm{Si}-\mathrm{CH}_{2}-\mathrm{CH}_{2}-\mathrm{CH}_{2}-\mathrm{Si}\right), 1134 \quad\left(\mathrm{Si}-\mathrm{CH}_{2}-\mathrm{CH}_{2}-\mathrm{CH}_{2}\right)$, $780\left(\mathrm{Si}_{-} \mathrm{CH}_{3}\right), 474$ (Si-Cl); ${ }^{1} \mathrm{H}$ NMR $400 \mathrm{MHz}: 1.6254$ (multiplet, 4H, $\mathrm{CH}_{2}$ ), 1.2037 (multiplet, $4 \mathrm{H}, \mathrm{CH}_{2}$ ), 0.8212 (multiplet, 4H, $\mathrm{CH}_{2}$ ), 0.2691 (singlet, 12H, $\mathrm{CH}_{3}$ ), $0.2004 p p m$ (singlet, $6 \mathrm{H}, \mathrm{CH}_{3}$ )

5. 1,1-Bis(chlorodimethylsilylpropyl) ether (1e). Bp. $120^{\circ} \mathrm{C}$ at $0.8 \mathrm{mmHg}$. FTIR (ATR, $\left.\mathrm{cm}^{-1}\right): 2935$ (C-H alkane), 2857(C-H alkane), 1409 (geminal dimethyl), 1123 (C-O), 466 (Si-Cl); ${ }^{1} \mathrm{H}$ NMR 400 MHz: 3.4994 (multiplet, $4 \mathrm{H}, \mathrm{CH}_{2}$ ), 1.7732 (multiplet, $4 \mathrm{H}, \mathrm{CH}_{2}$ ), 0.9805 (multiplet, $4 \mathrm{H}, \mathrm{CH}_{2}$ ), 0.5246ppm (singlet, $12 \mathrm{H}, \mathrm{CH}_{3}$ )

6. 1,6-Bis(Chloromethylphenylsilyl)Hexane (1f). Bp. $210^{\circ} \mathrm{C}$ at $0.5 \mathrm{mmHg}$. FTIR (ATR, $\mathrm{cm}^{-1}$ ):, 2970 (C-H alkane) 2912 (C-H alkane), Overtones between $1800-1975 \mathrm{~cm}^{-1}$ (aromatic phenyl groups), 1430 (methyl), 1123 (Si-Ph), 725 (Si-Ph), 472 (Si-Cl); ${ }^{1} \mathrm{H}$ NMR $400 \mathrm{MHz}$ : 7.3322 (multiplet, 6H, CH), 7.0149 (multiplet, 4H, $\mathrm{CH}$ ), 1.6236 (multiplet, $4 \mathrm{H}, \mathrm{CH}_{2}$ ) 1.1557 (multiplet, $4 \mathrm{H}, \mathrm{CH}_{2}$ ), 1.0045 (multiplet, $4 \mathrm{H}, \mathrm{CH}_{2}$ ), 0.7330 (singlet, $6 \mathrm{H}, \mathrm{CH}_{3}$ )

\section{Results and Discussion}

In order to verify that the hydrosilylation reaction went to completion, each product was analyzed using FTIR and NMR. The FTIR indicated the disappearance of the double bond and $\mathrm{Si}-\mathrm{H}$ vibration in the di-addition product. The results of the FTIR of the products showed the appearance of the Si-Cl peak, indicating the addition of the chlorosilyl group to the double bond. The NMR analysis was done to verify that the addition that took place was anti-Markonikov by analyzing the splitting patters, integration results, and the number of peaks. Addition of the chlorosilyl group to the terminal carbon allows for condensation polymerization of the monomers because the $\mathrm{Si}-\mathrm{Cl}$ bond is weak and can be replaced with $\mathrm{Si}-\mathrm{OH}$ in the presence of water, leading to rapid condensation polymerization.

\subsection{Reactant FTIR Analysis}

The FTIR spectra analysis of each of the reactants shown in Section 3 indicates that in all of the diene reactants, there were strong peaks which corresponds to the double bond being present. The critical functional groups to determine if the hydrosilylation reaction was successful are the double bond $\mathrm{C}-\mathrm{H}$ stretch vibrations and the $\mathrm{C}=\mathrm{C}$ stretching and bending vibrations. For example, in 1,5-hexadiene, these vibrational modes were seen at $3100 \mathrm{~cm}^{-1}$ (Alkene C-H stretch), $1600 \mathrm{~cm}^{-1}$ (Alkene C=C stretch), $990 \mathrm{~cm}^{-1}$ (Alkene $\mathrm{C}=\mathrm{C}$ bend), and $909 \mathrm{~cm}^{-1}$ (Alkene $\mathrm{C}=\mathrm{C}$ bend). The above peaks were present in all of the diene reagents used and thus should, if the hydrosilylation is successful, disappear in the product since the product should be free of double bonds. For the vinylic and allylic silane reactants, there were peaks located at $1600 \mathrm{~cm}^{-1}$ (vinylic silane stretch), $1000 \mathrm{~cm}^{-1}$ (vinylic silane bending), $1600 \mathrm{~cm}^{-1}$ (allylic silane stretch), and $1160 \mathrm{~cm}^{-1}$ (allylic silane bending). Those peaks should not be present in the product since the addition of the chlorosilyl group will remove the allylic and vinylic silane functionality. The FTIR spectra of the dimethylchlorosilane and methylphenylchlorosilane reveals a band near $2100 \mathrm{~cm}^{-1}$, which corresponds to Si-H stretching vibrational mode. It also shows another band which is located at $470 \mathrm{~cm}^{-1}$ that band pertains to the $\mathrm{Si}-\mathrm{Cl}$ stretching vibration. Should the reaction between 1,5-hexadiene and dimethylchlorosilane be successful for the di-addition product, the peaks at $2100 \mathrm{~cm}^{-1}$ (Si-H) and $1600 \mathrm{~cm}^{-1}(\mathrm{C}=\mathrm{C})$ should disappear and the peak at $470 \mathrm{~cm}^{-1}$ (Si-Cl) should remain.

\subsection{Reactant Proton NMR Analysis}

Table 2 through Table 8 show the proton NMR chemical shift values and peak assignment for the reactants. Bolded values represent highly de-shielded protons that should resonate significantly more upfield should the hydrosilylation goes to completion.

Table 2, Proton NMR Analysis of 1,5-Hexadiene

\begin{tabular}{|c|c|}
\hline Structure & Chemical Shift Value (ppm) \\
\hline Protons & $\mathbf{6 . 7 2}$ \\
\hline $\mathbf{A}$ & $\mathbf{5 . 8 6}$ \\
\hline $\mathbf{B}$ & 3.06 \\
\hline $\mathrm{C}$ & Ch \\
\hline
\end{tabular}


Table 3. Proton NMR Analysis of 1,7-Octadiene

\begin{tabular}{|c|c|}
\hline Structure & Chemical Shift Value (ppm) \\
\hline Protons & $\mathbf{5 . 9 7 6}$ \\
\hline $\mathbf{A}$ & $\mathbf{5 . 1 3 7}$ \\
\hline $\mathbf{B}$ & 2.236 \\
\hline $\mathrm{C}$ & 1.582 \\
\hline $\mathrm{D}$ &
\end{tabular}

Table 4. Proton NMR Analysis of Dimethylchlorosilane

\begin{tabular}{|c|c|}
\hline & B \\
\hline Structure & Cl- \\
& \\
& Bi- \\
\hline Protons A & Chemical Shift Value \\
\hline A & 5.38 \\
\hline B & 0.982 \\
\hline
\end{tabular}

Table 5. Proton NMR Analysis of Dimethyldivinylsilane

\begin{tabular}{|c|c|c|}
\hline Structure & $\mathrm{A} \rightleftharpoons$ & $\stackrel{\mathrm{B}}{ } \mathrm{A}$ \\
\hline Protons & \multicolumn{2}{|c|}{ Chemical Shift Value (ppm) } \\
\hline A & \multicolumn{2}{|c|}{6.965} \\
\hline $\mathbf{B}$ & \multicolumn{2}{|c|}{6.489} \\
\hline $\mathrm{C}$ & \multicolumn{2}{|c|}{0.969} \\
\hline
\end{tabular}

Table 6. Proton NMR Analysis of Diallyldimethylsilane

\begin{tabular}{|c|c|}
\hline Structure & $\underbrace{\mathrm{B}}_{\mathrm{C}}$ \\
\hline Protons & Chemical Shift Value (ppm) \\
\hline A & 5.821 \\
\hline B & 4.935 \\
\hline $\mathrm{C}$ & 1.614 \\
\hline $\mathrm{D}$ & 0.103 \\
\hline
\end{tabular}

Table 7, Proton NMR Analysis of Diallyl Ether

\begin{tabular}{|c|c|}
\hline Structure & Chemical Shift Value (ppm) \\
\hline Protons & $\mathbf{6 . 6 7 9}$ \\
\hline $\mathbf{A}$ & $\mathbf{6 . 0 4 6}$ \\
\hline $\mathbf{B}$ & 4.748 \\
\hline $\mathrm{C}$ & C \\
\hline
\end{tabular}

Table 8. Proton NMR Analysis of Methylphenylchlorosilane

\begin{tabular}{|c|c|}
\hline & \\
\hline & \\
\hline &
\end{tabular}

Each of the dienes produced proton NMR signals near $6.0 \mathrm{ppm}$ which in all of the dienes used, corresponds to the double bond region of the molecules. The double bond acts as an electron withdrawing group due to the high electron density shared between the two alkene carbons, therefore the protons involved in the double bond are much more de-shielded relative to the other alkane protons, therefore the peaks associated with the double bond are located farther downfield than the alkane protons. The farther the protons are from the double bond the more shielded they become and the more upfield they resonant in the proton NMR. The Si acts as an electron donating group and causes even more shielding of the protons adjacent to it, causing them to resonant much more upfield than would be typically expected. Should the hydrosilylation go to completion, there should be no peaks around $6.0 \mathrm{ppm}$ since the double bond would be broken and it would be replaced by a highly shielding silyl group. The $\mathrm{Si}$ is extremely shielding due to its large and polarizable electron cloud which allows it to act as an electron donating group. Therefore, if the silyl group is added to the double bond, all of the chemical shift values shown in the products should be shifted significantly upfield.

\subsection{Product FTIR Analysis}

Each of the products show no $\mathrm{C}=\mathrm{C}$ bending or stretching vibrational modes (988 and $1647 \mathrm{~cm}^{-1}$ respectively), indicating that the double bond was broken via hydrosilylation. There was a notable disappearance of the $\mathrm{Si}-\mathrm{H}$ peak at $2100 \mathrm{~cm}^{-1}$ as well as the appearance of the Si-Cl peak occurring at around $470 \mathrm{~cm}^{-1}$. Taking the FTIR spectrum of 1,6-Bis(chlorodimethylsilyl)hexane as an example, there were no peaks located at $1600 \mathrm{~cm}^{-1}$, indicating the loss of the double bond of the 1,5-hexadiene starting reagent. There was also the appearance of peaks at $1253 \mathrm{~cm}^{-1}$ (Si-CH 3 stretch), $788 \mathrm{~cm}^{-1}$ (Si-CH $\mathrm{CH}_{3}$ bend), and $469 \mathrm{~cm}^{-1}$ (Si-Cl stretch). Indicating that the dimethylchlorosilyl group was added to the double bond of 1,5-hexadiene. This same trend occurred in the 1,8-Bis(chlorodimethylsilyl)octane product which showed the disappearance of the Si-H stretch at $2100 \mathrm{~cm}^{-1}$ and the $\mathrm{C}=\mathrm{C}$ stretch at $1600 \mathrm{~cm}^{-1}$ as well as the appearance of methylsilane peaks at $1256 \mathrm{~cm}^{-1}$ and $790 \mathrm{~cm}^{-1}$ and the 
appearance of the chlorosilane peak at $469 \mathrm{~cm}^{-1}$. The allylic and vinylic silanes used as starting reagents also showed the disappearance of the vinylic and allylic silane group stretching vibration at $1600 \mathrm{~cm}^{-1}$ and the appearance of the chlorosilane peak at around $470 \mathrm{~cm}^{-1}$. The 1,1-Bis(chlorodimethylsilylethyl)-1,1-dimethylsilane and 1,1-Bis(chlorodimethylsilylpropyl)-1,1-dimethylsilane showed the specific positioning of the chlorosilyl group since they showed peaks at $1134 \mathrm{~cm}^{-1}$ and $1200 \mathrm{~cm}^{-1}$ which correspond to a disilylethylene and disilylpropylene group respectively, showing evidence of anti-Markonikov addition.

\subsection{Product Proton NMR Analysis}

Table 9 through Table 14 show the proton NMR peak assignments and chemical shift values for the six products of the hydrosilylation reaction.

Table 9. Proton NMR Analysis of 1,6-Bis(chlorodimethylsilyl) hexane

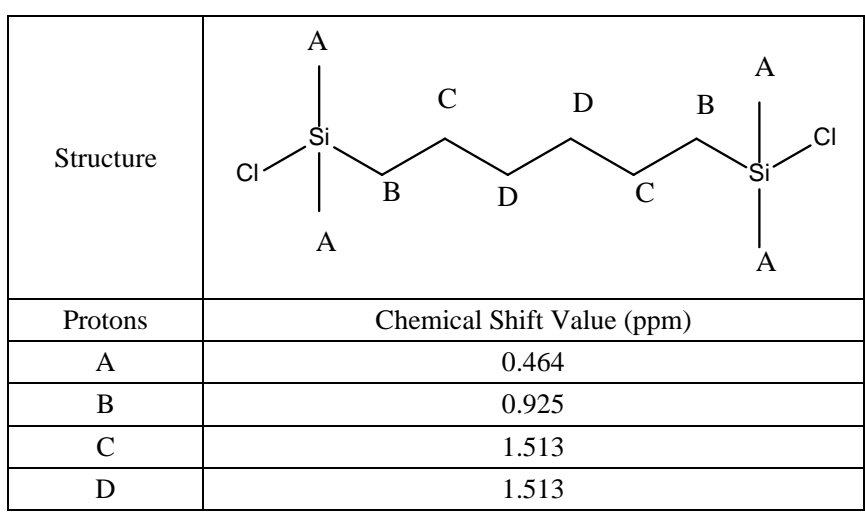

Table 10. Proton NMR Analysis of 1,8-Bis(Chlorodimethylsilyl)octane

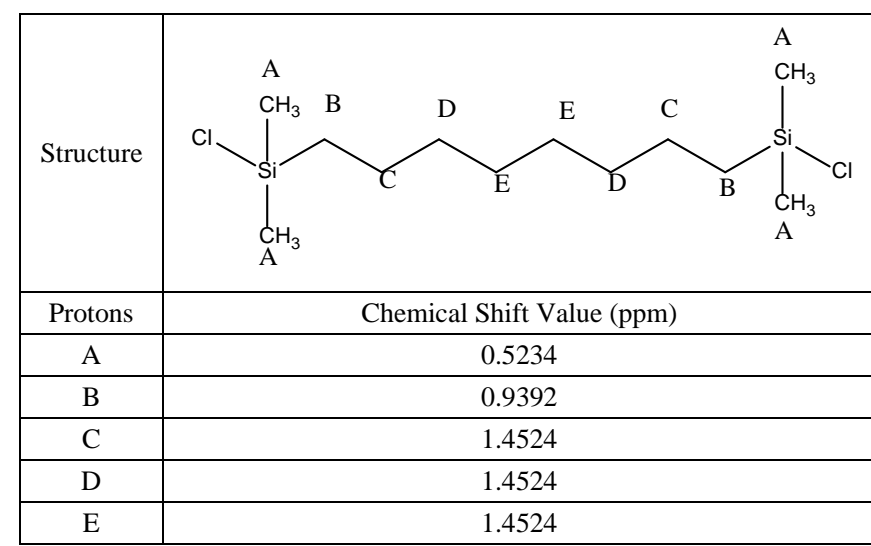

Table 11. Proton NMR Analysis of 1,1-Bis(chlorodimethylsilylethyl)1,1-dimethylsilane

\begin{tabular}{|c|c|c|}
\hline & & \\
& &
\end{tabular}

Table 12. Proton NMR Analysis of 1,1-Bis(chlorodimethylsilylpropyl)1,1-dimethylsilane

\begin{tabular}{|c|c|c|}
\hline & Chemical Shift Value (ppm) \\
\hline Structure & Chotons & 0.2691 \\
\hline $\mathrm{A}$ & 1.2037 \\
\hline $\mathrm{B}$ & 1.6254 \\
\hline $\mathrm{C}$ & 0.8212 \\
\hline $\mathrm{D}$ & 0.2004 \\
\hline $\mathrm{E}$ &
\end{tabular}

Table 13. Proton NMR Analysis of 1,1-Bis(chlorodimethylsilylpropyl) ether

\begin{tabular}{|c|c|}
\hline & Chemical Shift Value (ppm) \\
\hline Protons & 0.5246 \\
\hline $\mathrm{A}$ & 0.9805 \\
\hline $\mathrm{B}$ & 1.7732 \\
\hline $\mathrm{C}$ & 3.4994 \\
\hline $\mathrm{D}$ &
\end{tabular}

Table 14. Proton NMR Analysis of 1,6-Bis(chloromethylphenylsilyl) hexane

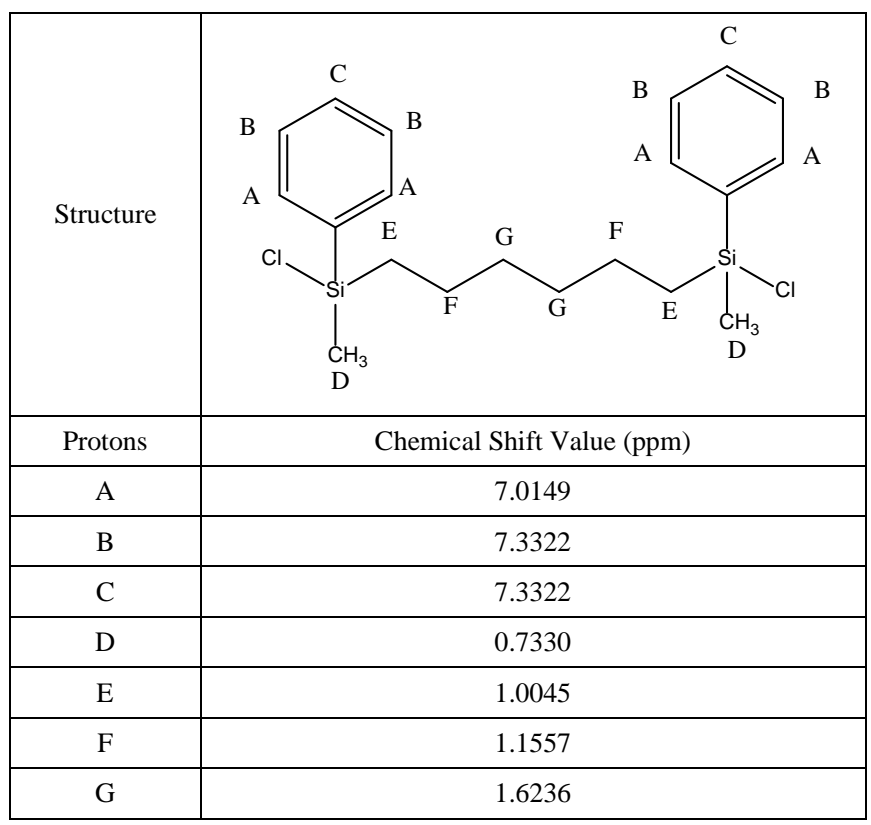

The proton NMR indicates the disappearance of the double bond in the structure due to the fact that there are no peaks located above $2.0 \mathrm{ppm}$ other than the aromatic protons present in 1,6-Bis(chloromethylphenylsilyl)hexane. The peaks present in the products are also located further upfield relative to the starting materials, indicating that the silyl group was also added to the double bond since the $\mathrm{Si}$ acts as an electron donating group and shields neighboring 
protons from the external magnetic field. The proton NMR showcases the fact that the addition of the chlorosilyl group occurred on the least substituted carbon (anti-Markonikov). This can be shown by examination of 1,6-Bis(chlorodimethylsilyl) hexane. If the addition of the chlorosilyl group was to the more substituted carbon, then there would be a peak corresponding to 2 Hydrogens which would be a multiplet at around 0.2 ppm labeled $\mathrm{C}$ on Figure 4, there would also be a triplet peak at around $0.8 \mathrm{ppm}$ that had an integration of 6 Hydrogens labeled B on Figure 4. Since there are no such peaks present in 1,6-Bis(chlorodimethylsilyl) hexane's proton NMR, it can be shown that the addition occurred on the least substituted alkene carbon. This same argument can be applied to the other products, in each example, there would be two extra methyl groups, rather than two methylene groups and therefore the integration and splitting patterns on the NMR support the hypothesis that addition of the chlorosilyl group occurred on the least substituted alkene carbon. Table 15 summarizes all the hydrosilylation products including their boiling points, molecular weights, refractive indices, and percent yields. The data in Table 15 clearly shows that as the complexity and the length of the backbone increases, as well with the addition of the aromatic group on the side-chain, the boiling points and refractive indices increase.<smiles>[B]C(CPC([B])[Si](C)(C)Cl)[Si](C)(C)Cl</smiles>

Figure 4. Hypothetical Markonikov Hydrosilylation Product of 1,5Hexadiene Reacting with Dimethylchlorosilane

Table 15. Structures and Properties of Hydrosilylation Products

\begin{tabular}{|c|c|c|c|c|}
\hline Monomer & $\mathrm{BP}\left({ }^{\circ} \mathrm{C}\right)$ & M.W. (g/mol) & Refractive Index & Percent Yield \\
\hline 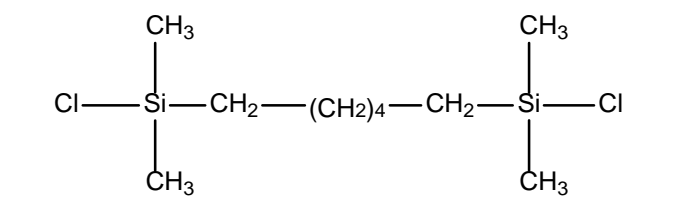 & 90.0 at $1 \mathrm{~mm} \mathrm{Hg}$ & 271.37 & 1.4536 & $75 \%$ \\
\hline $\mathrm{Cl}-\left.\right|_{\mathrm{CH}_{3}} ^{\mathrm{CH}_{3}}-\mathrm{CH}_{2}-\left(\mathrm{CH}_{2}\right)_{6}-\mathrm{CH}_{2}-\left.\right|_{\mathrm{CH}_{3}} ^{\mathrm{SH}_{3}}-\mathrm{Cl}$ & 128 at $1 \mathrm{~mm} \mathrm{Hg}$ & 299.43 & 1.4559 & $76 \%$ \\
\hline 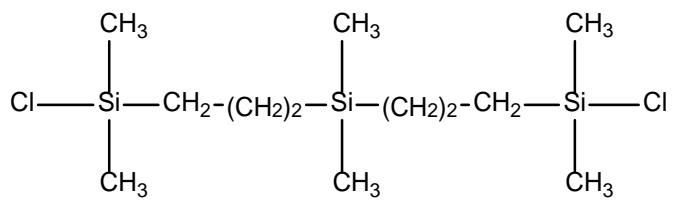 & 132 at $0.4 \mathrm{~mm} \mathrm{Hg}$ & 327.51 & 1.4591 & $75 \%$ \\
\hline $\mathrm{Cl}-\left.\right|_{\mathrm{CH}_{3}} ^{\mathrm{Si}}-\mathrm{CH}_{2}-\mathrm{CH}_{2}-\mathrm{O}-\mathrm{CH}_{2}-\mathrm{CH}_{2}-\left.\right|_{\mathrm{CH}_{3}} ^{\mathrm{Si}_{3}}-\mathrm{Cl}$ & 120 at $0.8 \mathrm{~mm} \mathrm{Hg}$ & 287.37 & 1.4631 & $78 \%$ \\
\hline $\mathrm{Cl}-\left.\right|_{\mathrm{SH}_{3}} ^{\mathrm{CH}-}-\mathrm{CH}_{2}-\mathrm{CH}_{2}-\left.\right|_{\mathrm{CH}_{3}} ^{\mathrm{CH}_{3}}-\mathrm{CH}_{2}-\mathrm{CH}_{2}-\left.\right|_{\mathrm{CH}_{3}} ^{\mathrm{SH}_{3}}-\mathrm{Cl}$ & 110 at $0.2 \mathrm{~mm} \mathrm{Hg}$ & 301.47 & 1.4534 & $74 \%$ \\
\hline 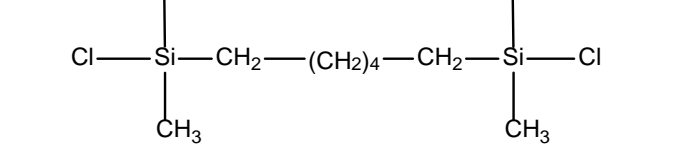 & 210 at $0.5 \mathrm{~mm} \mathrm{Hg}$ & 401.57 & 1.5398 & $74 \%$ \\
\hline
\end{tabular}


General Condensation Polymerization Scheme for Hybrid Siloxane Monomers

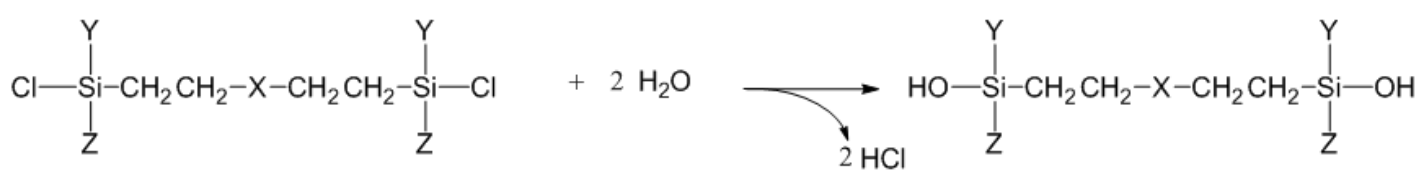<smiles>[X]CC[Si]([Z])(O)CC[Si]([Y])([Z])O[Si]([Y])([Z])CC[X]C[Si]([Z])(O)O[Si]([Z])([Y])O</smiles><smiles>[X]CC[Si]([Z])([Y])O[Si]([Z])(C)O</smiles>

Figure 5. Generalized Condensation Polymerization Reaction Scheme of Modified Siloxane Monomers

\section{Conclusion}

Hydrosilylation using the Karstedt's catalyst provides a convenient and effective synthetic route to the development of modified silicone monomers summarized in Table 15. The products can be easily characterized via refractive index, FTIR, and proton NMR in order to give structural insight and confirm the correct product was synthesized. These hybrid silicone monomers can be easily polymerized in the presence of water via condensation polymerization, whereby the $\mathrm{Cl}$ leaving group is replaced with $\mathrm{OH}$ which allows for rapid polymerization of the monomer unit. The generalized condensation polymerization scheme is shown in Figure 5 [1]. FTIR and NMR analysis consistently show the anti-Markonikov addition of the chlorosilyl group to the terminal carbon of the alkene double bond. FTIR showed that in the di-addition product that the double bond peak associated with the $\mathrm{C}-\mathrm{H}$ stretch $\left(3000 \mathrm{~cm}^{-1}\right)$ of an alkene, the $\mathrm{C}=\mathrm{C}$ stretch $\left(1600 \mathrm{~cm}^{-1}\right)$ of alkene as well as the $\mathrm{Si}-\mathrm{H}$ stretch $\left(2100 \mathrm{~cm}^{-1}\right)$ disappeared in the final product, showing the disappearance of the double bond and the addition of the chlorosilyl group. A new peak corresponding to the Si-Cl stretch $\left(470 \mathrm{~cm}^{-1}\right)$ was shown to appear, providing evidence for the addition of the chlorosilyl group to the double bond. The proton NMR analysis showed that the addition of the chlorosilyl group occurred in an anti-Markonikov fashion such as what was predicted through the literature. This was determined through the integration, the splitting patterns, and the number of peaks present in the proton NMR. The NMR also showed further evidence of the double bond disappearing due to the notable absence of highly deshielded protons in the 6.0-5.0 ppm region as would be typical of an alkene, along with the highly shielded methyl protons attached to the Si which is present around $0.5 \mathrm{ppm}$. This general procedure can be adapted for any compound containing terminal double bonds; however, this process is constrained by temperature and pressure considerations as well as carbon-chain length and chlorosilyl substituents.

\section{Acknowledgements}

We acknowledge the support from Hofstra University HCLAS Faculty Research and Development Grant.

\section{Statement of Competing Interests}

The Authors have no competing interests.

\section{List of Abbreviations}

ATR- Attenuated Total Reflectance

FTIR- Fourier Transform Infrared Spectroscopy

NMR- Nuclear Magnetic Resonance Spectroscopy

B.P.- Boiling Point

M.W.- Molecular Weight

${ }^{1}$ H- Hydrogen

STP- Standard Temperature and Pressure

R.T.- Room Temperature

Ph- phenyl

\section{References}

[1] Kuhn, F; Nuyken, O; Putzien, S; "Functionalized Polysilalkelene Siloxanes (Polycarbosiloxanes) by Hydrosilylation- Catalysis and Synthesis”, Progress in Polymer Science, 688-713, September 2009.

[2] Barnes, GH; Speier, JL; Webster, JA; "The Addition of Silicon Hydrides to Olefinic Double Bonds. II. The Use of Group VIII Metal Catalysts” J Am Chem Soc, 974-979, 1957.

[3] Karstedt, BD; "Platinum-Siloxane Complexes as Hydrosilation Catalysts” US patents 3775452. Assigned to General Electric Co.; 1973.

[4] Kogure, T; Ojima, I; "Hydrosilylation of Dienes, Acetylenes, and Carbonyls Catalyzed by Transition Metal Complexes” Rev Silicon Germanium Tin Lead Compd 1981.

[5] Kopylova, LT; Lukevits, E; Pukhnarevich, VB; Voronkov, MG; "Prospects for Hydrosilylation” Lituana 1992.

[6] Brook, MA; "Silicon in Organic, Organometallic and Polymer Chemistry” Weinheim, Germany: Wiley VCH; 2000.

[7] Roy, A; "A Review of Recent Progress in Catalyzed Homogenous Hydrosilyation.” Adv Organomet Chem, 55-59, 2008.

[8] Marciniec, B; "Hydrosilylation: A Comprehensive Review on Recent Advances” Adv Silicon Sci, 391-398, 2009.

[9] Boutevin, B; Guida-Pietrasanta; "Polysilalkylene or Silarylene Siloxanes as Hybrid Silicones.” Adv Polym Sci, 179-187, 2005.

[10] Sanchez, JC; Trogler, WC; "Hydrosilylation of Diynes as Route to Functional Polymers Delocalized Through Silicon” Macromol Chem Phys, 1527-1540, 2008.

[11] Abdellah, L; Boutevin, B; Youssef, B; "Synthesis and Applications of Photocrosslinkable Polysiloxanes” Progr Org Coat, 201-236, 1994

[12] Maxson, MT; Norris, AW, Owen, MJ; "Fluorosilicones In: Scheiers J, editor. Modern Fluoropolymers." Wiley, 359-372, 1997. 
[13] Roessing, M; “Additives in Adhesive Formulations: Wetting Agents- Boon or Bane?” Adhaesion Kleben Dichten, 22-27, 2009.

[14] Almeida, DF; Dias, TC; Lin, S; "Silicone Copolymers and Elastomers Derived From Natural Oils” Dow Corning Corporation, 2008.

[15] Madec, J; Marechal, EJ; “A New Route for Silicon-Containing Block Copolymer Synthesis” Polym Prepr, 814-815, 1993.

[16] Hocker, H; Riedel, J-H; "Preparation and Characterization of Polymers with Pending UV-absorber Groups I. Polymers Based on Poly(dimethylsiloxane).” J Appl Polym Sci, 573-579, 1994.

[17] Xie, Y; Xu, X; Zhang, C; "Recent Development of Organosilicon
Quaternary Ammonium Salt as Antimicrobial Agent” Huagong Jishu Yu Kaifa, 25-28, 2008.

[18] Herrwerth, S; Koenig, F; Maurer, T; Stadtmueller, S; "New Phosphated organopolysiloxane Derivatives and Their Use for Improving The Water-Resistance of Leather and Textiles” German Patent DE 102006047898. Assigned to Evonik Goldschmidt GmbH, 2008.

[19] Bender, W; Krumpfer, A; Krumpfer, J; Longenberger, T; Ryan, K; "The Art of Silicones: Bringing Siloxane Chemistry to the Undergraduate Curriculum.” J Chem Educ. 1682-1690, 2017.

[20] Wacker "Silicones, Compounds and Properties” 2011. 